\title{
ECONOMIC, SOCIAL AND ENVIRONMENTAL VULNERABILITY TO DROUGHT IN THE NORTHWEST RIVER BASIN SYSTEM, MEXICO
}

\author{
DAVID ORTEGA-GAUCIN, HEIDY V. CASTELLANO \& JESÚS DE LA CRUZ \\ Mexican Institute of Water Technology, Mexico
}

\begin{abstract}
Vulnerability to drought is the degree to which a system is susceptible to damage by drought and incapable of coping with its adverse effects. This article presents a method to calculate drought vulnerability indices in the Northwest River Basin System, Mexico. The method is based on the concept of vulnerability developed by the Intergovernmental Panel on Climate Change (IPCC, 2007), which differentiates three components of vulnerability: degree of exposure, sensitivity and adaptive capacity. Each of these components is represented by a set of relative indicators at the municipal level that allow for the determination of three basic types of vulnerability: economic, social and environmental, which converge in overall vulnerability. The successful use of the method in the Northwest River Basin System shows that it can be applied to the rest of river basin systems in Mexico, and it can also be adapted to be used at the state or national level. The strength of the method lies in its approach as an objective analytic procedure that makes it possible to identify the most vulnerable municipalities from economic, social and environmental perspectives, which is useful in managing resources and efforts to reduce vulnerability to drought in the different regions of the country.

Keywords: adaptive capacity, degree of exposure, drought, sensitivity, vulnerability
\end{abstract}

\section{INTRODUCTION}

Drought is a natural phenomenon, an intrinsic part of climate to which every part of the planet is exposed, even its rainiest regions. Droughts are characterized by their inevitability, and they are still scarcely predictable [1]. The phenomenon lacks an epicentre or a definite trajectory, its progress is slow and gradual, and it covers vast geographical extents; as a consequence, identifying its spatiotemporal limits and providing help to affected populations are challenging endeavours.

Vulnerability to drought is inversely related to the degree of development in the affected areas: whereas developed countries can usually withstand drought without serious consequences, since they possess the structural and economic means to face it, drought can spell hunger, poverty, migration and reduced well-being and quality of life in marginalized areas. The technological level of a region or country, as well as its organizational, institutional and social performances, is a key element in vulnerability to drought. An example of these differences in vulnerability can be observed when comparing Mexican and American farmers living near the border between their countries, where they share similar physical and biological conditions in contrast with their different social, political, economic and historical backgrounds [2]. Clearly, the former are more vulnerable than the latter.

As a consequence, water scarcity due to drought can be a decisive factor for some settlements to be abandoned by their working-age inhabitants (especially in arid and semiarid areas in the North), who prefer to seek job opportunities in large cities or abroad. These 'ghost towns', where at best remain only women, children and old people who make their livings from the meager products of the land and the resources sent by their young who have migrated, are an irrefutable proof of the scope and impact caused by droughts [3]. Recent research demonstrates that when crop yields - especially corn - are reduced due to drought, a significant increase in migration from Mexico to the United States is observed [4]. 
In this context, as an attempt to cope with the effects of drought by means of adequate risk management strategies, and in response to the severe drought that affected most of the country in 2011 and 2012, the Mexican federal government launched the National Program Against Drought (PRONACOSE, for its acronym in Spanish) with the goal of implementing a series of preventive actions to mitigate and reduce the vulnerability of populations to this natural phenomenon [5]. It is therefore important to assess vulnerability in each river basin system in the country bearing in mind that the risk of disaster by drought depends not only on the degree of rainfall scarcity and the duration and geographical reach of the phenomenon but also on vulnerability conditions that increase the chance of disaster when drought takes place.

This article describes our method for calculating drought vulnerability indices (VIs) in the Northwest River Basin System (Mexico) using relative indicators at the municipal scale. The method can be used by decision makers and officials responsible for developing public policies in identifying the most critical investments to reduce vulnerability and in delineating and proposing effective risk management actions from the economic, social and environmental perspectives of the problem.

\section{METHOD}

For a better understanding of the multiple dimensions of vulnerability, our method is based on the concept created by the Intergovernmental Panel on Climate Change [6], which explains vulnerability as a result of three different components: degree of exposure (DE), sensitivity $(S)$ and adaptive capacity (AC). Degree of exposure is defined as the possibility of a system to change as a result of a potentially destabilizing situation, be it positive or negative; sensitivity refers to the extent to which a system responds to environmental variations and adaptive capacity has to do with the system's capability to fit or adjust itself to new conditions in its environment. Degree of exposure and sensitivity represent the potential impact $(I)$ of the phenomenon (in other words, the expected amount of damage), and adaptive capacity is a measure of the extent to which potential impact can be avoided; therefore, vulnerability equals potential impact minus adaptive capacity, as expressed by the following equation:

$$
V=f(I-\mathrm{CA})=f(\mathrm{GE}+S-\mathrm{CA})
$$

Based on eqn (1), higher degrees of exposure and sensitivity result in higher vulnerability to drought, whereas higher adaptive capacity in comparison with the other two parameters represents lower vulnerability to drought.

Additionally, we must consider the different types of vulnerability: physical, economic, political, institutional and educational vulnerability, among others [7]. Accordingly, this study analyses economic, social, environmental and overall vulnerability to drought; what follows is a description of these concepts:

- Economic vulnerability: It is a consequence of an indirect relationship between income level and drought impact, which increases the risk of disaster due to insufficient funding for production, low wages, unemployment, underemployment and job instability, among others.

- Social vulnerability: This concept refers to the insecurity and defencelessness experienced by communities, families and individuals when their life conditions are threatened by drought. Poverty, marginalization and social backwardness, as well as difficult access to health care, education and leisure services inhibit the capacity to prevent, mitigate and promptly respond to a disaster situation due to hydrological deficit. 


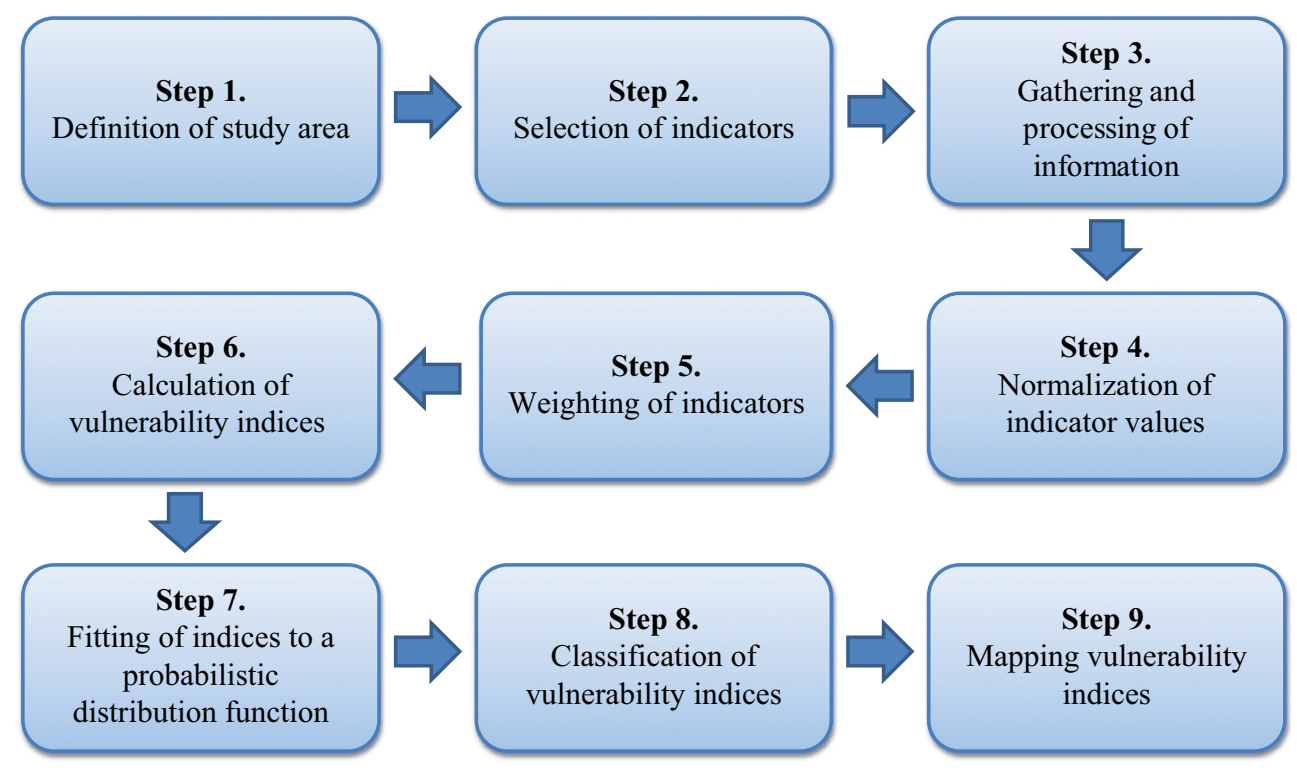

Figure 1: Steps of the method employed to calculate drought vulnerability indices in the Northwest River Basin System.

- Environmental vulnerability: This concept is related to an intrinsic susceptibility of the environment or its natural resources to be negatively affected by the lack of water; all living beings need certain environmental conditions for their development, but when nature can be deteriorated as a result of the destruction of environmental assets, ecosystems become highly vulnerable to hazards such as drought.

- Overall vulnerability: The three types of vulnerability previously described are integrated by this concept, in which economic, social and environmental factors converge.

Based on these concepts, we developed a nine-step method, which is shown in Fig. 1. The first step consists in selecting the study area; in steps $2-4$, indicators are chosen, information is processed and indicators are normalized; in step 5, the specific weight of each indicator is determined; step 6 consists in calculating VIs by multiplying the normalized indicator by its specific weight; in step 7, indices are fitted to the beta distribution function; in step 8, indices are classified in five degrees of vulnerability and, finally, the vulnerability map for the river basin system in question is obtained in step 9.

The nine steps included in the proposed method are described in the following sections.

\subsection{Definition of study area}

The National Water Commission (CONAGUA, for its acronym in Spanish) has divided the Mexican territory into 13 river basin systems to better administrate the country's water (Fig. 2). This study selected the Northwest River Basin System, a notably arid region. This river basin system has a surface area of $197,586 \mathrm{~km}^{2}$ (10\% of the national territory), and it consists of 71 municipalities in the state of Sonora and 7 in the state of Chihuahua (78 total municipalities). 


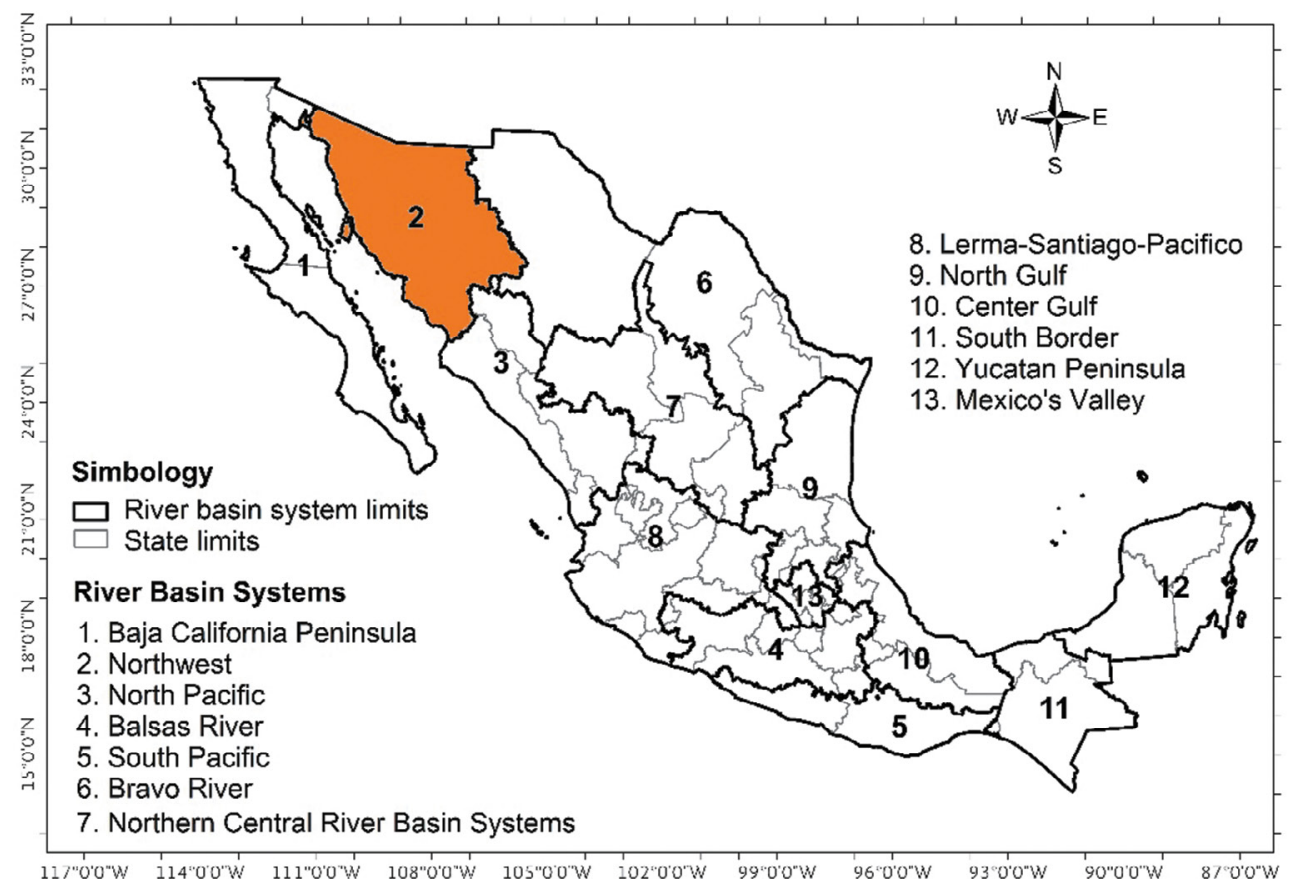

Figure 2: Boundaries of Mexican river basin systems and location of the Northwest River Basin System (grey).

\subsection{Selection of indicators}

Several criteria were taken into account to select the indicators, although the most determinant was direct relevance to the factor measured by the indicator and availability of municipal data (or how easily data could be calculated) in the form of figures, indices, rates or proportions obtainable from widely used national databases (INEGI, CONAPO, CONEVAL, etc.). In this way, 24 indicators were chosen and employed to build a matrix with the indicators grouped based on the three vulnerability components (exposure, sensitivity and adaptive capacity) and the four types of vulnerability (economic, social, environmental and overall), as shown in Table 1.

As shown in Table 1, overall vulnerability to drought is calculated using all the previously described indicators in the procedure explained below.

\subsection{Gathering and processing of information}

This process consists in gathering the necessary information to determine the value of each indicator considered for analysis based on the formulas and information sources presented in Table 2, which also lists the main information sources identified to calculate or obtain the indicators. 
Table 1: Matrix showing the selected indicators, grouped by type and component of vulnerability to drought.

\begin{tabular}{|c|c|c|c|c|}
\hline \multirow{3}{*}{\multicolumn{2}{|c|}{$\begin{array}{l}\text { Type of } \\
\text { vulnerability }\end{array}$}} & \multicolumn{3}{|c|}{ Components of vulnerability } \\
\hline & & $\begin{array}{l}\text { Degree of } \\
\text { exposure } \\
\text { (ED) }\end{array}$ & $\begin{array}{l}\text { Sensitivity } \\
(S)\end{array}$ & $\begin{array}{l}\text { Adaptive capacity } \\
\text { (AC) }\end{array}$ \\
\hline & & \multicolumn{3}{|c|}{ Indicators } \\
\hline \multirow[t]{3}{*}{ Overall } & Economic & $\begin{array}{l}\text { - Population } \\
\text { density (persons/ } \\
\mathrm{km}^{2} \text { ) } \\
\text { - Unemployed } \\
\text { population in } \\
\text { working age }(\%)\end{array}$ & $\begin{array}{l}\text { - Value of irrigation } \\
\text { and rainfed } \\
\text { agricultural } \\
\text { production } \\
\text { (thousands of } \\
\text { pesos) } \\
\text { - Value of livestock } \\
\text { production } \\
\text { (thousands of } \\
\text { pesos) }\end{array}$ & $\begin{array}{l}\text { - Surface } \\
\text { rehabilitated for } \\
\text { irrigation (ha) } \\
\text { - Technified } \\
\text { agriculture } \\
\text { surface (ha) } \\
\text { - Total length of } \\
\text { rural roads }(\mathrm{km})\end{array}$ \\
\hline & Social & $\begin{array}{l}\text { - Population in } \\
\text { poverty (\%) } \\
\text { - Population } \\
\text { without health } \\
\text { care insurance } \\
(\%) \\
\text { - Illiterate } \\
\text { population }(\%)\end{array}$ & 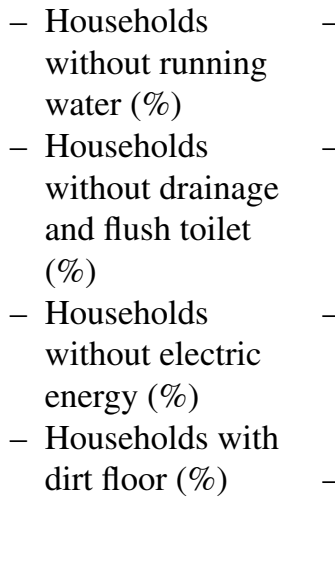 & $\begin{array}{l}\text { - Annual per } \\
\text { capita income } \\
\text { (dollars) } \\
\text { - Beneficiaries of } \\
\text { Oportunidades } \\
\text { programme } \\
\text { (\%) } \\
\text { - Beneficiaries } \\
\text { of Liconsa } \\
\text { programme } \\
\text { (\%) } \\
\text { - Average } \\
\text { schooling years } \\
\text { (dimensionless) }\end{array}$ \\
\hline & Environmental & $\begin{aligned} \text { - } & \text { Degree of } \\
& \text { watershed } \\
& \text { exploitation } \\
& \text { (dimensionless)* } \\
\text { - } & \text { Degree of aquifer } \\
& \text { exploitation } \\
& \text { (dimensionless)* }\end{aligned}$ & $\begin{array}{l}\text { - Deforestation (\% of- } \\
\text { critical forest area) } \\
\text { - Surface affected by }- \\
\text { forest fires (ha) } \\
\text { r }\end{array}$ & $\begin{array}{l}\text { - Re-forested } \\
\text { surface (ha) } \\
\text { - Protected natural } \\
\text { areas (\% of total } \\
\text { surface) }\end{array}$ \\
\hline
\end{tabular}

*Due to their relevance in the analysis of drought, these two indicators are included in the three types of vulnerability: economic, social and environmental. 


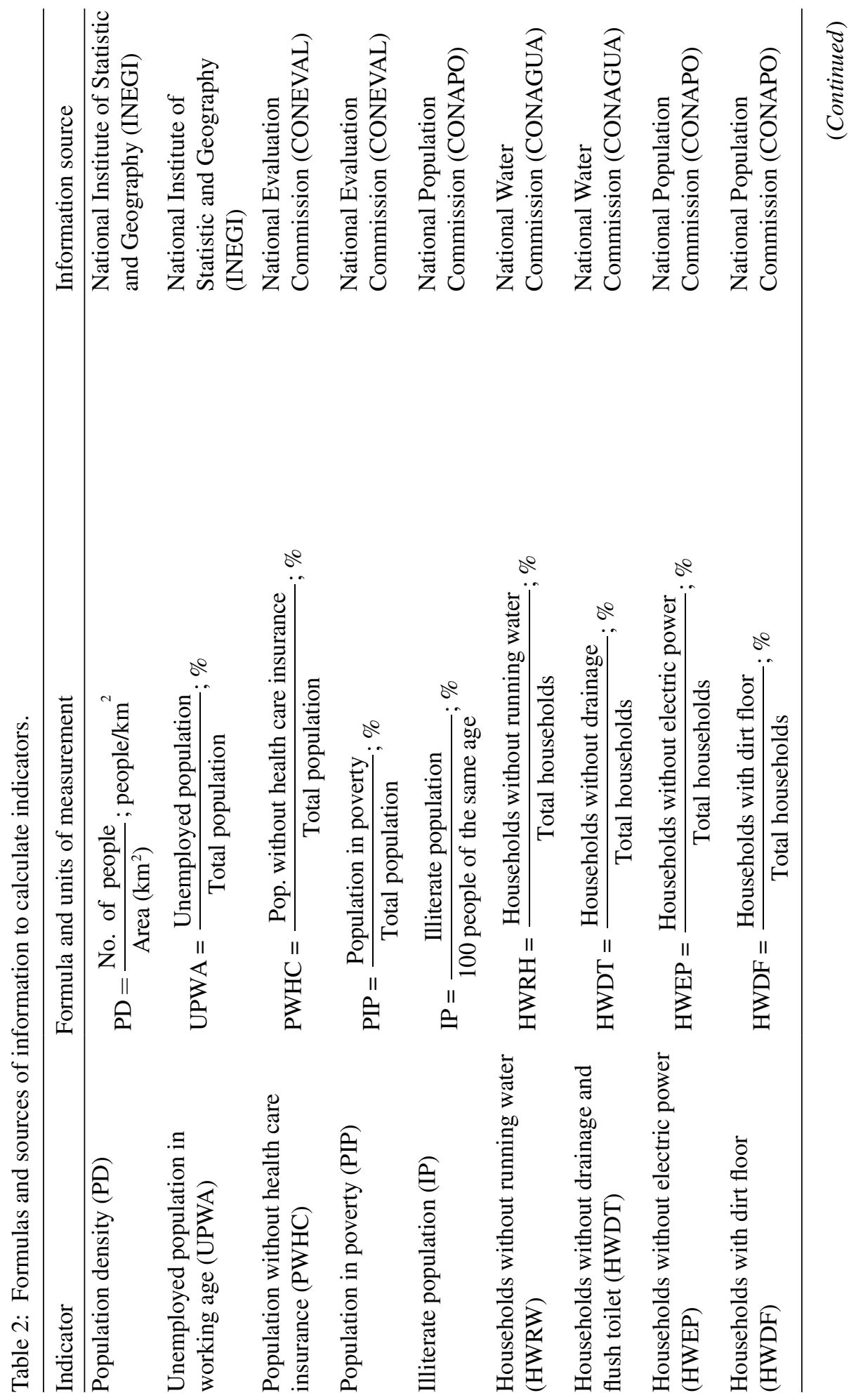




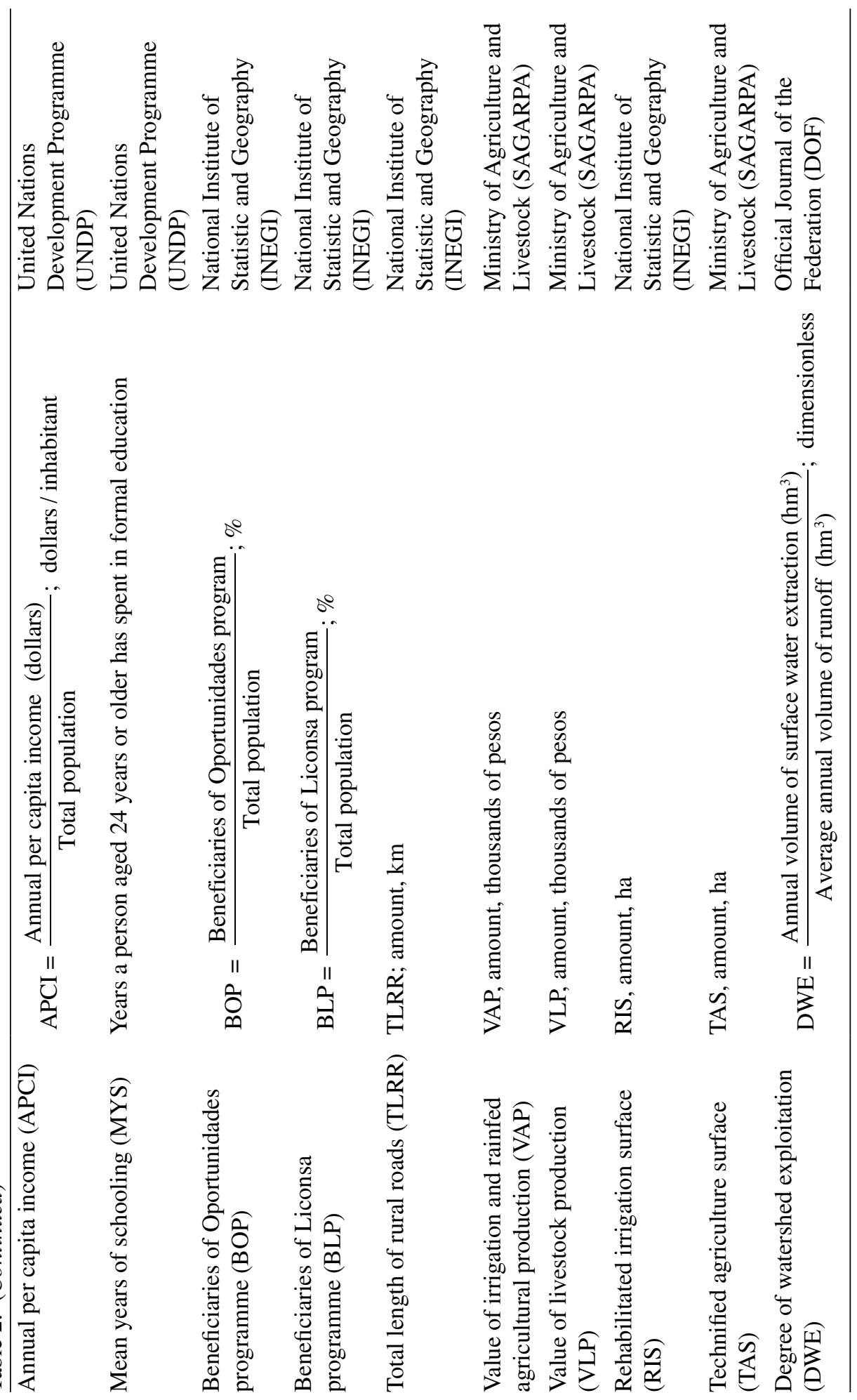




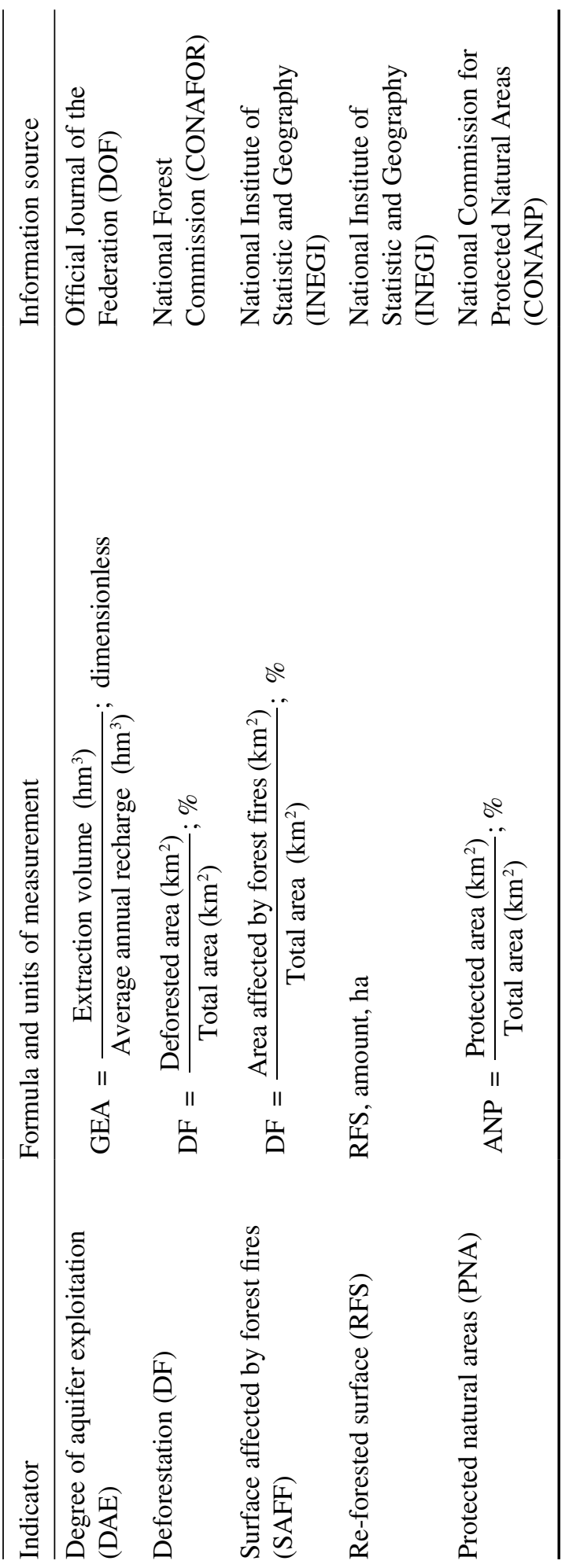




\subsection{Normalization of indicator values}

Given that indicators were expressed in different units of measurement, their values were normalized so that all of them were expressed as dimensionless values between 0 and 1 . To carry out this procedure, we first identified the indicator's functional relationship with vulnerability to drought. There are two possible types of functional relationships: according to the indicator value, vulnerability may increase or decrease. In the first case, the relationship is direct and is identified with symbol $\uparrow$; in the second case, the relationship is inverse and is indicated with symbol $\downarrow$. The indicators grouped under ED and $S$ have a direct relationship $(\uparrow)$ with vulnerability, whereas the relationship is inverse for indicators grouped under AC $(\downarrow)$. Once we identified the positive or negative impact of the indicators on vulnerability, indicator values were normalized using the following equations:

The expression $(\uparrow)$ was used for indicators with a direct functional relationship:

$$
X_{i}=\frac{x_{i}-x_{\min }}{x_{\max }-x_{\min }}
$$

In the case of indicators with an inverse functional relationship $(\downarrow)$, the expression was

$$
X_{i}=\frac{x_{\max }-x_{i}}{x_{\max }-x_{\min }}
$$

where, in both equations, $X_{i}$ is the normalized value of variable $x_{i}$, and $x_{\min }$ and $x_{\max }$ are the minimum and maximum values of dataset $x_{i}$, respectively.

2.5 Weighting of indicators

After obtaining the normalized indicator values, we calculated their weights by the method proposed by Iyengar and Sudarshan [8], which uses the following expression:

$$
W_{i}=\frac{1}{\left(\sigma_{i}\right)\left(\sum_{i=1}^{n} 1 / \sigma_{i}\right)} .
$$

where $W_{i}$ is the normalized indicator weight $i ; \sigma_{i}$ is the standard deviation of the set of values for indicator $i$; and $n$ is the number of selected indicators.

This weighting method prevents abnormally large variations in one or many indicators to overshadow the contribution of the rest of the indicators.

\subsection{Calculation of VIs}

In order to obtain overall vulnerability indices (OVIs), the economic, social and environmental vulnerability indices (EVI, SVI and EnVI, respectively) were calculated using the following formula:

$$
\text { EVI, SVI, EnVI }=\sum_{i=1}^{n} X_{i} W_{i}
$$


where $X_{i}$ is the normalized value of indicator $i ; W_{i}$ is the weight of normalized indicator $i$; and $n$ is the number of indicators associated with each type of vulnerability.

After that, OVIs were calculated assuming a weight $W_{i}$ of $1 / 3$ for each one of its components:

$$
\mathrm{OVI}=\frac{\mathrm{EVI}}{3}+\frac{\mathrm{SVI}}{3}+\frac{\mathrm{EnVI}}{3}
$$

\subsection{Fitting of indices to a probabilistic distribution function}

The obtained VIs were classified into categories by fitting the indices to a beta probabilistic distribution following recommendations by Iyengar and Sudarshan [8], who assert the adequacy of this type of distribution for classification purposes, since it is generally skewed and it takes values within the interval $(0,1)$. The beta function probability density is given by

$$
f(z)=\frac{z^{a-1}(1-z)^{b-1}}{\int_{0}^{1} z^{a-1}(1-z)^{b-1} d z} .0<z<1 ; \text { and } a, b>0
$$

where mean $\mu$ and variance $\sigma^{2}$ of variable $z$ are determined by

$$
\begin{gathered}
\mu=\frac{a}{a+b} . \\
\sigma^{2}=\frac{a b}{(a+b)^{2}(a+b+1)} .
\end{gathered}
$$

The following equations are obtained when both expressions are algebraically simplified to find parameters $a$ and $b$ :

$$
\begin{gathered}
a=\alpha=\mu\left\{\frac{\mu(1-\mu)}{\sigma^{2}}-1\right\}, \\
b=\beta=a\left\{\frac{1-\mu}{\mu}\right\} .
\end{gathered}
$$

Using the previous two equations, parameters $a(\alpha)$ and $b(\beta)$ were determined using an Excel $^{\circledR}$ spreadsheet, which also allowed us to obtain the probability of occurrence of the VIs fitted to the beta probabilistic distribution.

\subsection{Classification of VIs}

$\mathrm{VI}_{i}$ were classified according to their probability of occurrence, first by multiplying the obtained probability values so as to express them as percentages, and after that by determining five equally sized percentile categories (20\% each), which defined five degrees of vulnerability, as shown in Table 3. 
Table 3: Vulnerability to drought classification categories.

\begin{tabular}{lc}
\hline Degree of vulnerability & Value of percentile \\
\hline Very low & $0<\mathrm{VI}_{i} \leq 20$ \\
Low & $20<\mathrm{VI}_{i} \leq 40$ \\
Moderate & $40<\mathrm{VI}_{i} \leq 60$ \\
High & $60<\mathrm{VI}_{i} \leq 80$ \\
Very high & $80<\mathrm{VI}_{i} \leq 100$ \\
\hline
\end{tabular}

\subsection{Mapping VIs}

VIs were mapped by $\mathrm{ArcGis}^{\circledR}$ software using National Geostatistic Framework [9] data as a baseline, which allows for the accurate reference of statistical information to its corresponding geographical locations, which in this case are municipalities.

\section{RESULTS}

In this section, results of the Northwest River Basin System are presented as an application example of the method described earlier. Figure 3 shows the economic, social, environmental and overall vulnerability maps. As can be appreciated in the maps, the most economically vulnerable municipalities (where population density is highest, as well as economic activity as a consequence) are located in the state of Sonora; among these is Hermosillo, the state capital, which is characterized by its intense industrial, agricultural and stockbreeding activities. The most socially vulnerable municipalities (those with highest poverty, marginalization and social backwardness indices) are located in the state of Chihuahua, along its border with Sonora, in the Sierra Madre Occidental: a region of steep topography that complicates access to basic sanitary services, drinking water, electric power and so on.

The maps also show that the most environmentally vulnerable municipalities, where ecosystems are most fragile in case of drought, are mainly located in the state of Sonora, along the cost of the Gulf of California, where aquifers have been overexploited as a result of excessive use of water for irrigation purposes, which has caused the intrusion of saltwater into phreatic zones. Finally, when the three types of vulnerability are taken together, the municipalities of Nogales and Hermosillo (Sonora) and Madera (Chihuahua) are found to be the most vulnerable; in overall terms, these are the municipalities where urgent actions are required to mitigate potential negative effects of drought in the future.

\section{CONCLUSIONS}

Despite the fact that drought cannot be prevented, there are ways to attenuate its impact and reduce the losses of affected populations. The best strategy to cope with drought should start by evaluating vulnerability, which will serve different purposes: to prioritize the implementation of preventive and mitigation measures, to understand where and how to improve adaptive capacities, to identify where and how exposure and sensitivity should be decreased, to optimize the distribution of resources and, more generally, to support better water management in the different river basin systems. The method described in this article, which was applied to the Northwest River Basin System, Mexico, can be applied to each of the 26 river basin systems in the country, and it could as well be used at the state or national level. The main advantage of the method is its approach as an objective analytic procedure that allows for the 


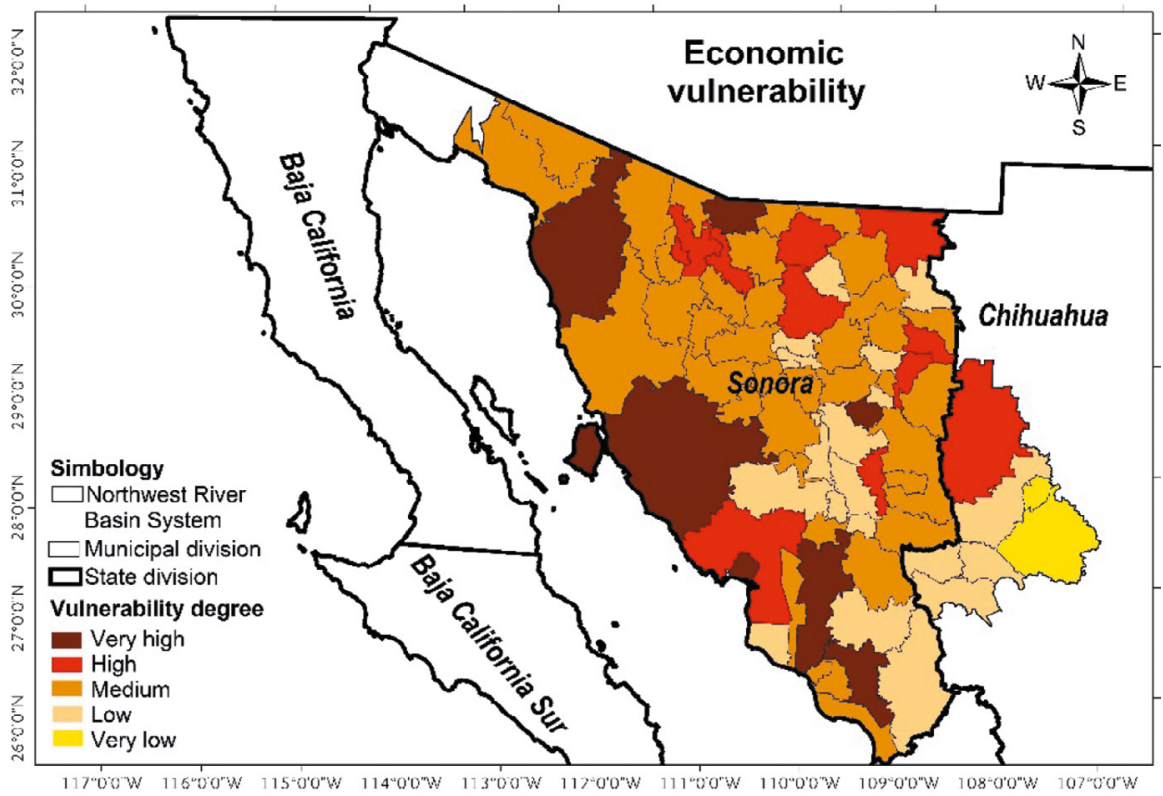

(a)

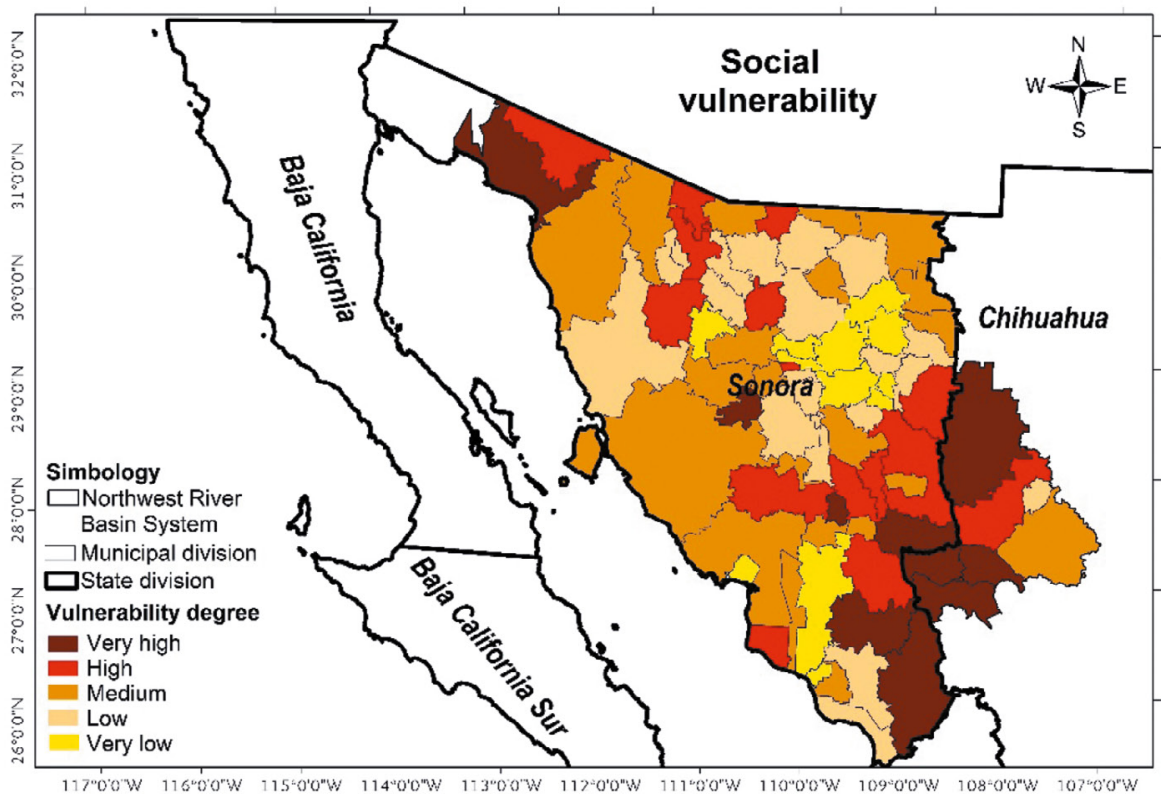

(b)

Figure 3: Economic (a), social (b), environmental (c) and overall (d) maps of vulnerability to drought in the Northwest River Basin System. 


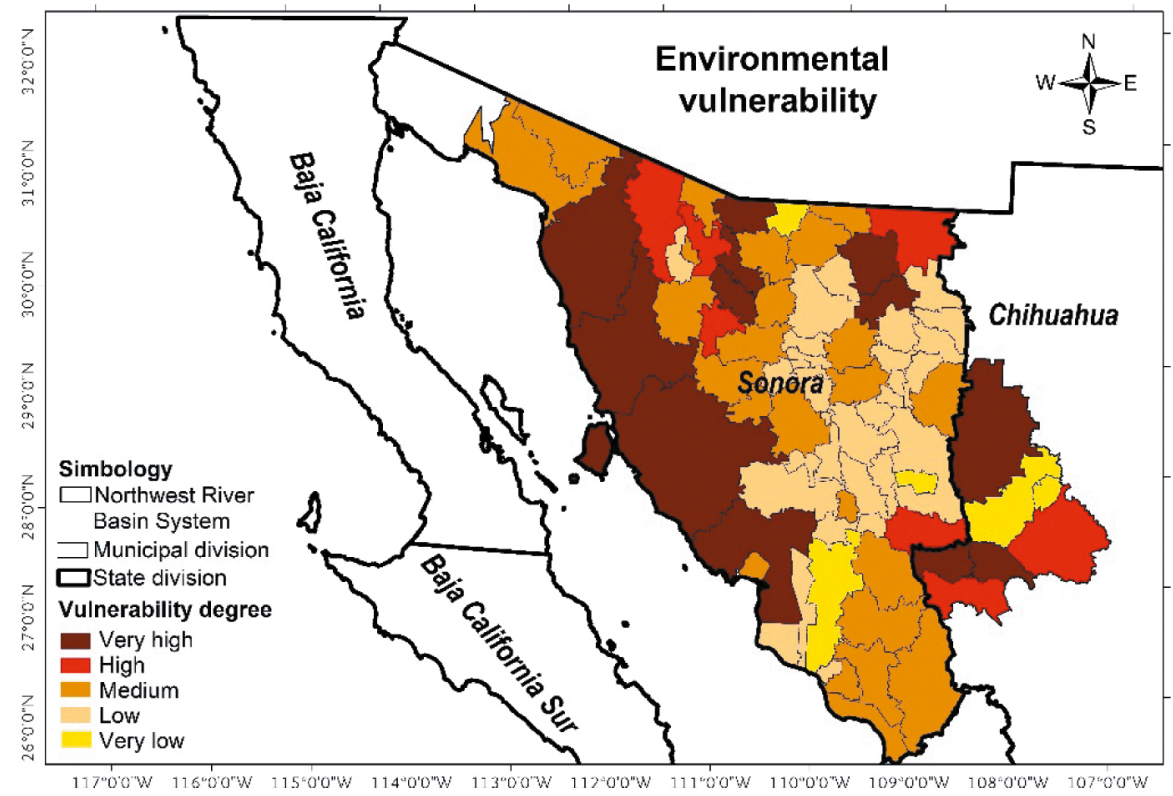

(c)

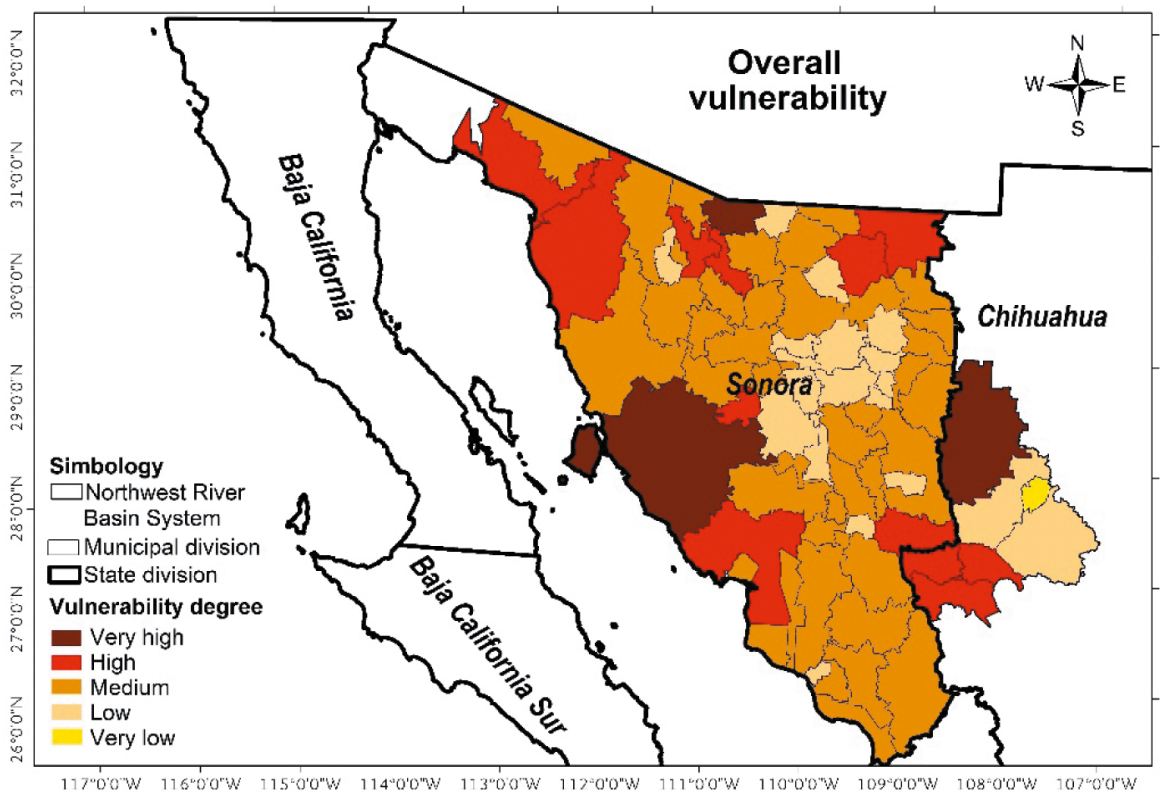

(d)

Figure 3: (Continued) 
identification of highly vulnerable areas from economic, social and environmental points of view, which in turn enables a better management of resources and efforts to reduce vulnerability to drought in the different regions of the country.

\section{REFERENCES}

[1] Kim, T., Valdés, J.B. \& Aparicio, J., Frequency and spatial characteristics of droughts in the Conchos River Basin, Mexico. Water International, 27(3), pp. 420-430, 2002. DOI: 10.1061/(ASCE)1084-0699(2000)5:2(145).

[2] Vásquez-León, M., West, C.T. \& Finan, T.J., A comparative assessment of climate vulnerability: agriculture and ranching on both sides of the US-Mexico border. Global Environmental Change, 13, pp. 159-173, 2003. DOI: 10.1016/S0959-3780(03)00034-7.

[3] Velasco, I., Ochoa, L. \& Gutiérrez, C., Sequía, un problema de perspectiva y gestión. Región y Sociedad, XVII(34), pp. 35-71, 2005. DOI: 10.22198/rys.2005.34.a615.

[4] Feng, S., Krueger, A.B. \& Oppenheimer, M., Linkages among climate change, crop yields and Mexico-US cross-border migration. Proceedings of the National Academy of Sciences, 107(32), pp. 14257-14262, 2010. DOI: 10.1126/science.1114722.

[5] Arreguín-Cortés, F., López-Pérez, M., Ortega-Gaucin, D. \& Ibáñez-Hernández, O., La política pública contra la sequía en México: avances, necesidades y perspectivas. Tecnología y Ciencias del Agua, 7(5), pp. 63-76, 2016.

[6] Panel Intergubernamental de Expertos sobre el Cambio Climático (IPCC), Cambio Climático 2007, Informe de Síntesis, Contribución de los Grupos de Trabajo I, II y III al Cuarto Informe de Evaluación del Panel Intergubernamental de Expertos sobre el Cambio Climático, WMO-UNEP: Ginebra, Suiza, 2007.

[7] Wilches-Chaux, G., La vulnerabilidad global. Los desastres no son naturales, comp. A. Maskrey, Red de Estudios Sociales en Prevención de Desastres en América Latina: Puerto Limón, Costa Rica, pp. 11-47, 1993.

[8] Iyengar, N.S. \& Sudarshan, P., A method of classifying regions from multivariate data. Economic and Political Weekly, 17(51), pp. 2048-2052, 1982.

[9] Instituto Nacional de Estadística y Geografía (INEGI), Marco Geoestadístico Nacional, INEGI: Aguascalientes, Ags., 2010. 